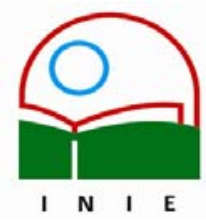

Actualidades Investigativas en Educación

Revista Electrónica publicada por el

Instituto de Investigación en Educación

Universidad de Costa Rica

ISSN 1409-4703

http://revista.inie.ucr.ac.cr

COSTA RICA

\title{
LA DISCIPLINA EN LA ESCUELA SECUNDARIA: SIGNIFICADOS DE ALUMNOS EN RIESGO DE EXCLUSIÓN
}

DISCIPLINE IN JUNIOR HIGH SCHOOL: MEANINGS OF STUDENTS

IN RISK OF EXCUSIÓN

Volumen 7, Número 3

pp. 1-20

Este número se publicó el 15 de diciembre 2007

José Inés Lozano Andrade

La revista está indexada en los directorios:

LATINDEX,$\underline{\text { REDALYC, IRESIE}, ~ C L A S E, ~ D I A L N E T, ~ D O A J, ~ E-R E V I S T @ S, ~}$

La revista está incluida en los sitios:

REDIE, RINACE, OEI, MAESTROTECA, $\underline{\text { HUASCARAN }}$ 


\title{
LA DISCIPLINA EN LA ESCUELA SECUNDARIA: SIGNIFICADOS DE ALUMNOS EN RIESGO DE EXCLUSIÓN DISCIPLINE IN JUNIOR HIGH SCHOOL: MEANINGS OF STUDENTS IN RISK OF EXCUSIÓN
}

\begin{abstract}
José Inés Lozano Andrade ${ }^{1}$
Resumen: Tomando como base la teoría de la resistencia de McLaren, y con auxilio de categorías derivadas de las visiones posmodernas, se analizan los significados que los alumnos en riesgo de exclusión tienen hacia la disciplina de escuelas secundarias en el Distrito Federal. Dichas escuelas se ubican en un contexto urbano en que el neoliberalismo y la posmodernidad han dejado hondas huellas en sus alumnos, mismas que se aprecian en sus significados hacia diferentes ámbitos de lo escolar. Se encuentra que en el contexto escolar, rígido y normalizador, estos estudiantes, con problemas de reprobación y de "mala conducta", construyen significados acordes a sus actitudes y que van desde la resistencia abierta hasta la indiferencia pura. Fundamentándose en una metodología cualitativa, se desarrollan categorías sociales que analizan cómo estos actores se manifiestan de variadas maneras encontrando mecanismos que desafían la vida cotidiana escolar caracterizada por la deslibidinización de sus deseos callejeros. Así, aunque persiste la idea de estudiar para ser "alguien en la vida", se procura "evadir las clases", cuestionando la labor docente y la poca significatividad de las asignaturas, a la vez que se rebelan ante la imposición de reglas que pretenden normar su "diferencia personal"
\end{abstract}

Palabras clave: RESISTENCIAS DEL ESTUDIANTE/ DISCIPLINA/ POSMODERNIDAD/ EXCLUSIÓN ESCOLAR/INDIFERENCIA/

\begin{abstract}
From the theory of resistance of Mclaren, and with the help of categories that come from posmodern visions, manifestations and meanings of students in high risk of scholastic exclusion of discipline in junior high school in Mexico City are analized, framed in an urban context where neoliberalism and posmodernity have deeply marqued students and all these influence their meanings throuhg different issues about shool. In this rigid context is promoved the formation of different attitudes that come from open resistance to pure indifference in the students with problems, what makes this educative space an interesting object for analisys. This reserch is based on a cualitative metodology, certains social categories are developed and reveal how students defy the daily rutines of school which is caracterized by the inibition of their street desires. So, although the idea of studing "to be someone in life" persists, students miss classes and constantly cuestion the role of teachers and the meaningless of school subjects, and defy the rules that pretend to standarize their "personal difference"
\end{abstract}

Keywords: RESISTANCE OF STUDENTS/ DISCIPLINE/ POSMODERNITY/ ADOLESCENTS/ SCHOLASTIC EXCLUTION/ INDIFFERENCE/

\footnotetext{
${ }^{1}$ Doctorado en Pedagogía de la Universidad Nacional Autónoma de México (UNAM), Maestría en Ciencias de la Educación de la UVM, Licenciado en Sociología de la UNAM. Actualmente es Profesor investigador titular " $\mathrm{C}$ " de tiempo completo en Escuela Normal Superior de México. Miembro del Sistema Nacional de Investigadores, nivel I en 2007. Consultor de UNICEF en el 2005.
}

Correo electrónico: [ines2101@yahoo.com

Artículo recibido: 9 de octubre, 2007

Aprobado: 12 de diciembre, 2007 


\section{INTRODUCCIÓN}

"La indiferencia crece. En ninguna parte el fenómeno es tan visible como en la enseñanza donde en algunos años, con la velocidad del rayo, el prestigio y la autoridad del cuerpo docente prácticamente han desaparecido... la enseñanza se ha convertido en una máquina neutralizada por la apatía escolar, mezcla de atención dispersada y escepticismo lleno de desenvoltura ante el saber." (Lipovetsky, 2005, p. 39)

La escuela secundaria en México se ha caracterizado por ser, dentro de la educación básica, un nivel con acentuadas problemáticas que hacen dudar del logro de las pretensiones oficialmente planteadas. Lo anterior se puede demostrar con diversos estudios, entre ellos los realizados por el Programa para la Evaluación Internacional de Estudiantes (PISA por sus siglas en inglés). En la aplicación de 2003, donde se evalúan las competencias lectoras, que complementan los resultados de un estudio anterior sobre competencia matemática en 2001, se obtuvo la conclusión general de que la mayoría de los jóvenes alcanza los niveles más bajos de competencia en estos ámbitos pues solo un $6.9 \%$ alcanzaron el más alto nivel y respecto a matemáticas, en la mayoría de las escuelas secundarias el nivel de competencia 0 es superior al 80\% (Vidal, 2004).

El Distrito Federal tiene problemas graves, aún cuando posee las mejores cifras a nivel nacional respecto al acceso, permanencia, reprobación, deserción y eficiencia terminal. Respecto a la reprobación, los autores coinciden en que esta es una de las principales causas de la deserción y señalan que en el DF un 18.2\% han tenido este problema en por lo menos una asignatura. La deserción es el problema que se encuentra oculto debajo del anterior, y en esta entidad, según los datos más recientes, es del $5 \%$ cifra que está por debajo de la media nacional que es del 6.8\%. También se menciona que la eficiencia terminal en el ciclo de 3 años es a nivel nacional del $79.7 \%$ y en el DF de $83.1 \%$. Todos estos datos sitúan a la secundaria en un estado crítico respecto a los demás niveles educativos. En suma puede afirmarse que la secundaria en México, es fuente de inequidad en donde, de inicio, no todos acceden a ella, y los que lo hacen, corren el riesgo de ser excluidos, en buena medida debido a los altos niveles de reprobación que hay en su interior (INEE, 2005; RIES, 2002).

Los factores de la reprobación y deserción pueden ser diversos y con pesos distintos en cada caso particular, pero pueden clasificarse en internos y externos en función de donde 
ocurren los fenómenos a los que se refieren, aún cuando se admite que las fronteras entre unos y otros son flexibles y complejas en sus relaciones. De acuerdo a una investigación documental elaborada para UNICEF (Lozano, 2005) se encontró que:

- Con relación a los factores internos, en primer lugar se mencionan las prácticas de enseñanza que han caracterizado a la escuela secundaria y que son rutinarias, tradicionales, autoritarias, memorísticas y tendientes a mantener el control del alumno como prioridad, aún sobre la pretensión del aprendizaje, (Quiroz, 2001; Sandoval, 2000) dentro del mismo rubro, se señalan prácticas de evaluación panópticas y cuantificadoras que invierten la relación de aprendizaje con la evaluación (Lozano, 2005, 2006) y especificando en este punto que la práctica docente es tendiente a favorecer al favorecido y desfavorecer al desfavorecido a través de representaciones, creencias o teorías implícitas que los docentes poseen y que guían su práctica a favor de ciertos sujetos más que de otros, generando una inequidad educativa que se puede explicar desde el currículo oculto. Un segundo aspecto a considerar como factor interno, es el de los planes de estudio, pues la secundaria se caracteriza por una sobrecarga de trabajo para el alumno, (aún con la Reforma de la Escuela Secundaria, que en su planteamiento no ha traído mejoras sustanciales en esto); Un tercer aspecto es la formación del docente que en este nivel es considerada como un factor que puede permitir comprender dichas prácticas, ya que, aunque los datos son diversos, los normalistas y quienes no lo son, establecen una competencia ríspida y desgastante, independientemente de que la formación que les caracteriza a ambos, no ha sido la adecuada. Aparte de lo anterior, como cuarto punto, están las condiciones laborales para los docentes que para muchos autores se han caracterizado por su excesiva carga y explotación, además de ser percibidas como una actividad cada vez más desacreditada socialmente. En quinto lugar, como factor interno, aun cuando depende de aspectos externos, se consideran diversos fenómenos que tienen que ver con la subjetividad del alumno respecto a la escuela y que pueden ser explicativos del fracaso escolar, tales como: la autopercepción que tiene respecto a su desempeño escolar, su autoestima, la noción sobre la seguridad del entorno y la escuela, las expectativas de los padres, las representaciones acerca de profesores y sus materias. Hay estudios recientes (SEP, 2005. Lozano, 2005a.), que han revelado que los hábitos de estudio, la situación socioeconómica, el estado emocional o el autoritarismo docente, de acuerdo a la percepción de los alumnos, no son factores relacionados directamente con este problema, pero si en cambio una 
percepción negativa acerca de los docentes y de la escuela, así como bajas expectativas laborales y económicas, además de considerar como factor de desánimo escolar a la estigmatización de que son objeto en el proceso escolarizado por parte de profesores, compañeros de aula y autoridades escolares, por cuestiones de clase, género o etnia, calificativos que en muchas de las ocasiones puede llevar al desinterés por la escuela y el fracaso.

- Entre los hallazgos relacionados con factores externos, la situación socioeconómica se considera como uno de los más relevantes en su efecto hacia la reprobación y deserción escolar, la pobreza en lo general se asocia directamente con la exclusión escolar, tanto los grupos marginales rurales, (sobre todo los indígenas), pero también los urbanos, siempre resultan los más perjudicados por un sistema escolar que de una o de otra manera favorece a los favorecidos y desfavorece a los desfavorecidos (Reimers, 1999; 2000). Otro factor externo fundamental asociado al anterior, es el de la familia, pues al respecto se afirma que los alumnos, cuyas madres en específico no poseen un nivel de escolaridad alto, son particularmente vulnerables a caer en la reprobación y deserción.

En resumen, podemos mencionar que el docente es el actor más indagado como factor asociado con la reprobación y deserción escolar, lo cual no quiere decir que sea el único y verdadero responsable de ello, sino el probable blanco favorito de la investigación educativa en esta problemática, ya que según esto, su formación, sus prácticas y sus condiciones laborales, así como la relación que establece con el currículo formal y la forma de desarrollar un currículo oculto son elementos fundamentales en este sentido. Por otro lado la investigación sobre el alumno es poca, anárquica y desarticulada, pues no se centra en el problema que nos interesa, ya que finalmente nos damos cuenta de que de este actor, pocos de los factores que tienen que ver con su subjetividad tienen relación directa con este fenómeno, en particular los significados acerca de la escuela, que poco han sido considerados aun en la investigación educativa para el análisis de este fenómeno. Sobre las condiciones externas, se puede afirmar que aunque existen relaciones estadísticas significativas que reflejan la inequidad de la escuela y su carácter reproductor de las diferencias sociales existentes, no se han elaborado investigaciones que en específico trabajen estas problemáticas, lo cual es necesario realizar. Por todo lo anterior, es recomendable analizar al alumno y sus significados hacia la escuela, recuperar la voz del excluido y antes de esto, del reprobado y a partir de esa voz, conjugada con la de los demás 
actores que le acompañan, realizar una valoración e interpretación de los factores que inciden y cómo inciden en la generación de esta problemática. Es así como nos preguntamos ¿Cuáles son los significados de los alumnos en riesgo de exclusión en torno a la disciplina escolar?

Estos significados se cristalizan, según evidencias proporcionadas por los informantes, en mecanismos de resistencia a la disciplina y que pueden ser desde el desafío o la provocación a las autoridades y maestros, hasta la indiferencia y apatía a lo que ocurre en la escuela, pasando por las diferentes formas de simulación y engaño que manejan para lograr sobrevivir al ambiente. En la institución donde se realiza esta investigación, dentro de la ciudad de México, existe una gran preocupación por imponer reglas de disciplina tales como: celebrar la ceremonia a la Bandera, portar uniforme, atender pasivamente en el aula los discursos y órdenes de los docentes, no ir al baño durante la clase, no decir groserías, mantener limpio el salón, no pintarse el pelo o traerlo muy largo, no besarse o tener contacto corporal, etc. Como resultado de esto, elaboran complejos comportamientos y significados que les permiten a algunos rebelarse abiertamente, a otros acomodarse en desacuerdo con estas reglas a fin de lograr mantenerse en la escuela y obtener su certificado o eventualmente evadirse de ella antes de concluir sus estudios. La relevancia de este estudio radica en que se elabora desde la perspectiva de estudiantes con problemas de "comportamiento" y "aprovechamiento" que frecuentemente han sido señalados y reportados por ello. Alumnos y alumnas que están señalados para el "fracaso escolar" a menos que acaten (aún sin aceptar) la lógica disciplinaria institucional. Conocer entonces sus percepciones, su subjetividad, es determinante para la comprensión del tema.

La teoría que orienta la interpretación de este objeto se ubica en las obras de la resistencia, particularmente en Peter Mclaren, quien propone analizarlas como cualquier manifestación sea o no conciente, que simbolice el desacuerdo con los rituales y rutinas que la escuela organiza para lograr sus propósitos deslibidinizadores y de dominio a sus miembros. En este sentido es como inserta la idea de una cultura escolar opuesta a la callejera que los alumnos tienen y llevan a la escuela de diversas maneras. Dicha cultura callejera se articula con aspectos de la vida posmoderna. Una vida que se define en la personalización o el narcicismo, el hedonismo, la indiferencia o el sin sentido, la trivialización de los actos y del saber científico, así como de la escuela. Lo cool y lo light en la vida, que se traslada de la esquina al centro escolar, además de otros aspectos que permiten comprender lo que 
ocurre en las escuelas (Lipovetsky, 2005; Hargreaves, 1996; Giroux, 1996.) Lo anterior se encuentra cruzado por el ambiente de esta escuela, situada en una ciudad excesivamente poblada y pauperizada, donde el sub y el desempleo son comunes, en una comunidad de desintegración familiar y delincuencia; dentro de un país atrasado y dependiente donde la globalización (promesa incumplida), ha traído más perjuicios que beneficios (para las mayorías), además de una reciente historia de crisis que los gobiernos neoliberales han acarreado con el consabido incremento de la delincuencia y la informalidad, todo ello, en evidente relación con la vida cotidiana escolar, porque la escuela no es, ni puede ser, un espacio aislado a ninguno de estos fenómenos.

\section{METODOLOGÍA}

En específico, este trabajo pretende describir e interpretar los significados que los alumnos construyen y manifiestan ante la disciplina que impone la escuela en general y la clase en particular y en función de ello, proporcionar elementos para la comprensión del problema de la exclusión escolar. Este estudio se realiza bajo una metodología cualitativa de investigación que se caracteriza por la búsqueda de significados y sentidos a los hechos humanos, a través de una descripción profunda y detallada que permita acceder a su interpretación y con ello a la comprensión a los mismos.

La técnica que se emplea para recopilar la información es la entrevista semiestructurada individual y en grupos focales, que obedece básicamente a la necesidad y desafíos que el objeto genera, pues el propósito planteado puede lograrse recopilando los discursos de los actores usualmente borrados y negados en el contexto escolar moderno: los alumnos. La técnica empleada para el análisis e interpretación de los resultados, así como su validación es la del análisis cualitativo de contenido. Este es un estudio de caso y aunque se aprecia que esta escuela es prototípica del nivel secundaria en este contexto espacio temporal, se es conciente de que lo que aquí ocurre, no se da en otros contextos similares, pues la cultura institucional y regional son diversas y complejas. La población de este estudio fue seleccionada basada en criterios específicos que siempre pretendieron encontrar informantes de calidad respecto al problema planteado; como producto de estos criterios, se accedieron a 33 informantes, 20 de género masculino y 13 del femenino; 15 de los cuales fueron entrevistados individualmente y el resto en entrevistas colectivas o grupos focales, donde una fue exclusiva para mujeres y otra para hombres. Cabe aclarar que estos alumnos eran los que más asignaturas reprobadas y reportes de trasgresión tenían en la escuela 
(algunos incluso estaban en posibilidades de causar baja en la institución por alguna de estas situaciones). El trabajo de campo se sistematizó y analizó con la técnica de análisis cualitativo de contenido (Buendía y otros, 1999. Taylor y Bogdan, 1996) que dieron una serie de resultados que se manifiestan en categorías sociales que adelante se analizan².

\section{ANÁLISIS Y DISCUSIÓN DE RESULTADOS}

El análisis de los significados y sentidos que los alumnos dan a los diferentes modos de actuar así como a las formas en que se representan sus realidades, no se puede alejar de la historia personal ni de los contextos en que se desarrolla la acción humana, tales como la escuela, el grupo, la comunidad misma. La familia en este caso, puede jugar un papel relevante para la comprensión del fenómeno de la exclusión escolar, por lo cual se incluye una visión de esta institución social.

Los profesionistas no envían a sus hijos a estas escuelas ${ }^{3}$ : Por ser esta una escuela pública enclavada en una región urbana y marginada de la ciudad de México que padece una serie de conflictos sociales tales como la existencia de bandas juveniles, drogadicción, alcoholismo y delincuencia, esta institución es en particular poco solicitada y deseada como opción educativa de este nivel ${ }^{4}$, aún por los mismos vecinos más acomodados del lugar, por ello la mayoría de quienes se matriculan en esta institución son provenientes de comunidades que mantienen características similares a las ya anotadas, hijos de familias con escaso capital cultural y económico (Bourdieu, 1982). De inicio pues hay que considerar este elemento como crucial: los alumnos no deseaban ansiosamente quedarse en esta escuela, sino que fue una asignación oficial dados los escasos y precarios resultados obtenidos en el nivel previo. Lo anterior no es de extrañar pues aunque en efecto hay excepciones, las ocupaciones y la situación socioeconómica de las familias de las cuales los informantes provienen son similares en esa escasez de recursos económicos y culturales. Las ocupaciones básicas de los padres eran: choferes, obreros, empleados y una tercera parte

\footnotetext{
${ }^{2}$ Como resultado del análisis de las entrevistas, se procedió a buscar las categorías sociales que emergían de las respuestas de los informantes. Estas categorías se presentan en negritas y revelan la manera en que los alumnos construyen su realidad social respecto a la disciplina escolar en este contexto espacio temporal específico. Se intenta a la vez realizar una interpretación de estos testimonios empleando elementos del contexto y a la vez de la teoría que se ha planteado anteriormente.

${ }^{3}$ A partir de aquí, los títulos de las categorías, no necesariamente es información textual, sin embargo, emergen de los testimonios vertidos por los alumnos estudiados y del análisis elaborado por el autor con base en estos, cual es el caso de esta categoría que se deduce por los niveles de escolaridad de los padres.

${ }^{4}$ Igualmente existen algunas afirmaciones que son inferencias de la información proporcionada de las entrevistas individuales y en grupo focal desarrolladas y que se usan indistintamente en la presentación de este apartado.
} 
comerciantes informales; de las madres la mayoría eran amas de casa, algunas trabajaban en labores domésticas o como obreras y pocas trabajaban como empleadas en oficinas desempeñando labores administrativas.

A decir de Reimers (1999), son doce los grados de escolaridad que se requieren en América Latina para que un buen porcentaje de la población emerja de la pobreza extrema, que en México, es escandalosa considerando que tenemos al hombre más rico del mundo. También se ha dicho que es la escolaridad de la madre, más que la del padre, definitoria en esta posibilidad. En el caso que nos ocupa, los datos son contundentes: la escolaridad de los padres es escasa, excepción hecha con tres informantes cuyos padres había concluido su bachillerato, la mayoría solo terminaron la secundaria y una parte menor solo la primaria; pero el caso de la escolaridad materna era aún más alarmante, pues una tercera parte concluyó la secundaria, otro tanto la primaria y el resto, aunque no es analfabeta, tenían estudios inconclusos de primaria.

Evidentemente los elementos del contexto familiar ya descritos repercuten en el capital cultural que los alumnos poseen y que a decir de varios autores, influyen en su rendimiento escolar, lo cual se ve mediado por las expectativas que los padres y madres de alguna manera, a través de sus lenguajes, manifiestan a sus hijos acerca de la escuela y su futuro ocupacional. Estudiar para que "sean alguien en la vida" es el mejor deseo de los padres y madres para sus vástagos y es lo que estos informantes han recibido como mensaje: ambiguo, complejo, cargado de ideología: se es nadie, solo estudiando se logra ser "Alguien". Por tanto, ser "Alguien" es: quien tiene escolaridad y dinero, quien manda y no es mandado. El colonialismo se actualiza en este mandato pocas veces cumplido, pero siempre deseado. El "ninguneo" a los pobres, sometidos, conquistados, explotados ha dado resultado en este sector de la población que todavía pone sus expectativas (aunque con pocas esperanzas) en la escuela para ascender socialmente. Sin embargo, aunque los padres creen y han construido una realidad correspondiente a su época, aquella en que había seguridad en las perspectivas y perspectivas de seguridad, los hijos conciben una distinta. No puede ser de otra manera, les ha tocado vivir a nivel mundial y nacional situaciones muy diferentes.

La globalización y la posmodernidad han dejado secuelas importantes en su forma de percibir la realidad escolar. Hargreaves (2000), Giroux (1996), Mc laren (1994) coinciden en señalar que existe una contradicción entre las condiciones de la vida social y las del mundo 
escolar, pues señalan que mientras que la escuela sigue siendo moderna, la sociedad ya es posmoderna, lo cual acarrea ciertas consecuencias que repercuten de diversas maneras en la escuela misma. La escuela, creada en la modernidad para resaltar e imponer a la ciencia como único saber legítimo, preocupada por la estandarización de valores basados en el éxito, el esfuerzo, el nacionalismo y otros más, centrada en prácticas disciplinarias, controladoras de los impulsos hedonistas de los actores, se encuentra frontalmente en contradicción con la apertura a nuevos saberes y a la desacreditación de la ciencia como aparato resolutivo de los problemas de la vida. La escuela con ello, comienza a ser deslegitimada en la medida en que es el centro difusor y generador del saber científico (tradicionalmente concebida desde el positivismo).

En particular Giroux (1996) por ejemplo, se centra en las actitudes (apatía y pesimismo con respecto al futuro), de los jóvenes a los que denomina fronterizos, por encontrarse en una situación generacional situada entre la modernidad y la posmodernidad.

Hoy, las esperanzas que se tenían con relación a la movilidad social y económica se han desvanecido en la mayoría de los países. Las condiciones económicas y laborales actuales a nivel mundial ponen en tela de juicio el papel de la educación. Es una generación para los cuales los medios se han vuelto un sustituto de la experiencia, al igual que en múltiple casos lo es la droga, con familias deshechas o con serios problemas de comunicación afectiva, los jóvenes, particularmente los adolescentes, ven a la escuela como un centro de diversión, un pasatiempo que difícilmente resolverá sus problemas económicos futuros, pero que debe cursarse como una necesidad socialmente impuesta mientras tienen la edad para trabajar, pero que además puede resultar, en ocasiones, divertida.

Lipovetsky (2005) se refiere a la indiferencia pura, al narcisismo y el hedonismo como características de la posmodernidad, que no solo afecta a los jóvenes sino a todos. La escuela, inserta en esta lógica posmoderna de búsqueda de la novedad, donde lo nuevo deja de serlo en cuanto llega, convirtiendo todo en viejo; con una incesante búsqueda de satisfacción del deseo, del placer personal, a la carta, se convierte en un mecanismo anacrónico de estandarización y de disciplina que contraría a lo anterior. En ese contexto la escuela es una institución caduca donde los alumnos deambulan mientras pasa el tiempo. Quizá por lo anterior Hargreaves (1996), advierte de una tendencia de la escuela a volverse aún más rígida y autoritaria ante esta circunstancia de anomia estudiantil y docente. En la 
investigación que nos ocupa la escuela está saturada de rutinas simbólicas, casi todas ellas en búsqueda del orden donde todos deben hacer lo que deben, donde y cuando deben. Intentando evitar a toda costa la contingencia, porque el mejor día es cuando es un día de rutina. Así la entrada a la escuela, el cierre de la puerta, el uniforme, el corte de cabello, el pase de lista en las clases, la revisión de la tarea, las bancas alineadas, el permiso para faltar, los exámenes, la distancia social que se mantiene con las autoridades escolares, los desfiles, los honores a la bandera y otros aspectos son evidentemente tendientes a la búsqueda de la disciplina entendida esta como la pasividad en el cumplimiento de los roles que los actores deben tener para el logro del orden escolar.

En suma, se percibe que la sociedad posmoderna actual esta vacía de sentido, no hay direcciones a donde dirigirse, las utopías han desaparecido y la ciencia ya no es un parámetro de seguridad, es decir, ya no se tienen esas perspectivas de seguridad, ni seguridad en las perspectivas, todo es sumamente incierto. Ante esta situación no es de extrañar que los sentidos y significados que se tienen hacia la escuela en este nivel sean vagos, poco construidos y más bien improvisados por que se percibe que la escuela es importante, pero limitando esa relevancia a la supuesta mejoría económica; al respecto los alumnos, recogiendo las expectativas de los padres (reveladoras de la ideología de dominio que subyacen en estas frases) señalan frecuentemente que estudian para "ser alguien en la vida". Al encontrar un significado y un sentido tan escueto y ambiguo con respecto a las expectativas escolares, cargado de ideología, es de esperarse que estos alumnos tengan comportamientos poco adhesivos con respecto a la institución escolar y sus propuestas disciplinarias y formativas, las cuales son resistidas de maneras variadas.

"Los alumnos aguantan las clases.": Es esta una expresión recurrentemente mencionada de distintas formas por los informantes:

“...si no hay clase, mejor para mí..."

“...cuando no llegan los maestros, tenemos dos horas libres..."

\footnotetext{
${ }^{5}$ Los testimonios presentados son producto de las entrevistas individuales y en grupo focal. No se distingue en este procedimiento los resultados obtenidos en la aplicación de una u otra técnica pues no presentaron diferencias sustanciales en la información vertida, e incluso la triangulación de estas técnicas sirvió para validar la información, ya que era muy similar en ambos casos.
} 
Entre otras frases más que recuperan el significado de estos sujetos que viven la clase con sufrimiento. Esperan que pronto acabe y que tengan tiempo libre abundante. Obviamente están divorciados del conocimiento que puedan obtener de ellas y si acaso están atentos a los procesos evaluatorios que incluyen su asistencia y orden. Hay entonces un sin sentido hacia el aprendizaje. En efecto, en tanto que no se interesan por desarrollarse académicamente en este nivel, manifiestan, muchas veces de manera no consciente, actitudes de inconformidad a lo que ocurre en sus clases cotidianas, las cuales tienen que ver con la incredulidad a los rituales escolares en general. Ejemplos de estos significados son los siguientes testimonios:

"Cuando no queremos que siga la clase simplemente nos empezamos a distraer o hacemos ruido, o le decimos al maestro, -¿sabe que?, no queremos que nos de clase - y a veces si nos hace caso..."

“... si la clase no me gusta, les decimos (a los maestros) que si puedo salir, que si me da permiso de ir al baño, si nos dice que si, hasta nos tardamos 15020 minutos, si la clase es de una hora, pues ya la recortamos....

A decir de Lipovetsky (2005, p. 39):

Es ese abandono del saber lo que resulta significativo, mucho más que el aburrimiento, variable por lo demás, de los escolares. Por eso el colegio se parece más a un desierto que a un cuartel... donde los jóvenes vegetan sin grandes motivaciones ni intereses. De manera que hay que innovar a cualquier precio: siempre más liberalismo, participación, investigación pedagógica y ahí esta el escándalo, puesto que cuanto más la escuela se dispone a escuchar a los alumnos, más estos deshabitan sin ruido ni jaleo ese lugar vacío.

Los alumnos viven en una sociedad prismática donde conviven rasgos tradicionales y modernos que se combinan con aspectos propios de la posmodernidad; carentes de sentido, sin conciencia política y social, cada vez más imbuidos en una lucha feroz por su individualidad, regados en bandas callejeras que sostienen a fuerza de la violencia su particularidad de la que se sienten orgullosos, sin un sentido político de cambio social humanitario, están insertos en una revolución indiferente señalan Cólom y Mélich (1996), en un "Let it be" constante que exige el derecho a su individualidad en una escuela que pretende estandarizar. Así, este sujeto pasa la vida en el salón haciendo diversas actividades que no tienen que ver con su desarrollo académico, pues esto pasa a un 
segundo término. Intentan pasarla lo mejor posible mientras que están "esperando que acabe la clase". La cual se ha convertido en una arena de lucha para no ser "atrapados por los maestros". Según sus propias expresiones:

“... sin palabras (se muestra el rechazo a la clase), platicando, riendo, no poniendo atención a la clase, aunque el maestro se enoje, pararnos y tirar basura, estar en la ventana viendo nada más, ...haciendo ruidos como empezar a mover las bancas, empezar a chiflar, a reírse, a eructar,..."

“... también les puedes decir que te sientes mal, que te deje ir a tomarte una pastilla, que estás mal de los riñones..."

El manejo del tiempo y las irrupciones a la clase son acciones cotidianas que manifiestan la inconformidad de los alumnos y alumnas. Son resistencias dice McLaren. Y lo son en la medida en que se oponen de distintas maneras a que el currículo formal se lleve a cabo de la forma en que se lleva a cabo (currículo vivido y oculto). Son formas de traer la cultura callejera, de los amigos, de la banda a la clase. En esta cultura hay informalidad, espontaneidad, policromía, flexibilidad y ante todo gozo. La escuela se preocupa por lo contrario. Hay mayor control disciplinario, más medidas correctivas y sancionadoras, más obligación. En una época en que los derechos son lo prioritario se puede acusar fácilmente al docente y escuela de violentar al alumno con "tanta" actividad escolar. Hasta el docente ha aprendido que es mejor bajar las exigencias hacia estos en esta escuela y así evitarse complicaciones.

Existen muchas maneras de evadir la clase, estas son empleadas por estos actores cuando no les interesa o no es lo suficientemente amena. Los comentarios siguientes obtenidos de una entrevista en grupo focal denotan lo anterior:

“... empezamos a gritar, a chiflar, nos empezamos a mentar la madre, le pegamos a las butacas, a modo que el maestro se llegue a desesperar..."

“... hacer ademanes para que todos se rían... hacer ruidos de animales, estornudos... el eructo.... lo hacemos para quitarnos de lo cotidiano..."

"Una forma frecuente era ponerse un pañuelo en la nariz y decir al maestro que le estaba sangrando para ir al baño...."

"Manejar o evadir el tiempo de la clase": según los resultados amplios son los recursos empleados para lograrlo y actividades de la clase y de esta manera apropiársela, no dejarla 
al arbitrio de la institución y del docente que intentarían si les es posible, disciplinar las actividades cotidianas de la clase y a sus actores. Algún informante, usando un concepto empleado por un docente con buena aceptación y logros de aprendizaje entre ellos, decía respecto al mismo: "nos quiere cooptar", evidenciando con esto una resistencia al aprendizaje aún con docentes que destacan. $Y$ es que en esto subyace la lógica del menor esfuerzo académico posible: entrar tarde, hacer lo menos posible, salir cuanto antes y obtener la mayor calificación posible. Las irrupciones son formas de evadir la monotonía de una clase que propone aprendizajes de contenidos que no les interesan a estos sujetos, como reflejan los siguientes comentarios:

“... luego no me gustan unas materias que nos dan, como álgebra... son muchos números, hay que aprender varias cosas..."

“... hay (asignaturas) que no tienen nada que ver (con la realidad) y me aburren mucho...mis padres me dicen que tengo que aprobar las materias para acabar la escuela, que si repruebo ya no voy a tener el certificado...que le eche ganas a todas (las asignaturas) aunque no me gusten porque en un futuro de algo me han de servir.... Cuando no hay papeles que demuestren que estudiaste, te dan empleos bajos o mal pagados..."

“... hay asignaturas que se imparten a lo mejor para que los maestros tengan trabajo o decir que se estudia muchas horas, no sé...si yo las escogiera dejaría por ejemplo mate y español, pus porque hay que saber leer y escribir ¿no? y además sumar, restar y eso..."

Incluso en algunos casos se llegan a medidas extremas con tal de impedir su desarrollo como provocar cortos circuitos, aventar bombas olorosas, esconderse del docente en colectivo, y otras igualmente denotativas del significado de lo escolar, por ejemplo, narra un alumno que:

Por ejemplo hoy teníamos examen de química y no queríamos que hubiera clases y lo que hicimos fue desconectar las lámparas y como ya era de las últimas horas pues ya no se veía nada y perdimos tiempo y ya no nos aplicó el examen el maestro..."

Aunque esta no es una situación generalizada entre los informantes, si se comparte en gran medida en ellos, quienes son los principales propulsores de estas medidas que finalmente acaban siendo ejecutadas por el grupo en colectivo. Todo esto finalmente son manifestaciones de rechazo a la clase, a sus contenidos, técnicas de enseñanza, 
mecanismos de evaluación y a los maestros mismos como tales, los cuales se conciben en este discurso como los representantes de la institución escolar y sus reglas.

¿La desconsideración o la ausencia del deseo?: Si hablamos de lo que el alumno quiere de la escuela, debemos anticipar que las razones educativas en estos sujetos están débilmente presentes y que su presencia en la misma se debe más a un mandato familiar que a un deseo personal. Cuando McLaren (1994) plantea que en la escuela existe una deslibidinización creemos que se refiere a la gran gama de imposiciones que la escuela plantea para la vida del estudiante.

Se piensa por parte de los informantes que el maestro exagera casi siempre su papel de impositor y represor del deseo, se habla de que en el salón se imponen reglas muy estrictas que no consideran en absoluto su deseo y que por lo tanto se olvida que son adolescentes inquietos y rebeldes, en busca de identidad, idea psicologizada que parece se ha difundido entre los mismos alumnos, e incluso docentes, actores ambos que a decir de Moscovici (1961), se convierten en "sabios aficionados" al reconstruir como representación social las teoría psicológicas de la adolescencia, que es empleada por estos para criticar en el caso de los maestros y para justificar en el caso de los alumnos las actitudes de ambos en clase: los primeros "controlando al adolescente inquieto, descontrolado", los segundos tratando de rebelarse ante lo impuesto pues dicen:

"... somos adolescentes":

“...Si el maestro se pone más estricto nos rebelamos más... más lo hacemos para hacerlo enojar..."

“... nadie te tiene que decir lo que tienes que hacer porque ya eres una señorita y uno se educa como uno cree que es lo correcto..."

“...además nunca te van a educar, porque si te dicen - isiéntate aquí o haz esto!nunca le vas a hacer caso... es lo mismo con los padres... entre más te prohíban las cosas, más lo haces...” “

Con otras prohibiciones o reglas ocurre lo mismo, pero es en la apariencia personal donde enfatizan más su defensa y su rebeldía. Por ejemplo afirman respecto a estas reglas que:

“... Es el gusto de uno... como peinarse o como verse, si te gustan peinados estrafalarios pus es cosa de uno... uno puede venir como quiera, hasta despeinado, o cabello corto, como sea..." 
El uso de gorras en el salón, los aretes o piercing en varones, uso del uniforme, los cortes de cabello "decentes" son algunas de esas características que los estudiantes defienden con vehemencia. La prohibición reiterada es fuente de rebeldía, aunque lo que predomina como actitud de manera más extendida sea el acomodo rebelde a esas circunstancias en la mayoría de los alumnos. La identidad personal es lo esencial en estas manifestaciones de rebeldía, es una forma de oposición que impugna a la disciplina por negar su deseo. Mclaren (1994), afirma al respecto que:

... Ios estudiantes rechazan la cultura del aprendizaje en el aula porque, para la mayor parte, está deslibidinizada (niega el erotismo) y esta influida por un capital cultural al cual los grupos subordinados tienen un acceso poco legitimado. La resistencia a la instrucción escolar representa una solución de parte de los estudiantes para no ser disimulados frente a la opresión; es una pelea en contra de que se borren sus identidades callejeras. Resistir significa pelear en contra de que se vigile la pasión y el deseo... (p. 230)

A pesar de lo anterior nos preguntamos si estos estudiantes tienen algún deseo o sentido "legítimo" hacia la escuela, que no sea el de convivir con sus amigos y alejarse de los quehaceres de su casa o incluso el de la obtención eventual del certificado si es que logran acomodarse en la escuela lo suficiente para ello, pues es de notar como ha mencionado Lipovetsky que el desarrollo e interés en lo académico es lo que se extraña más por su ausencia. Respecto a esto algunos comentarios denotativos son los siguientes:

"la neta, neta yo vengo a la escuela porque si no me regañan en mi casa, además me aburro porque me ponen a limpiar mi cuarto",

"no pus (sic) entre ir a la escuela o quedarme a ser el gato de mi casa, mejor voy, por lo menos ahí la cotorreo chido (sic)"

En ese sentido es como la idea de McLaren sobre la "deslibidinización" solo podría referirse a esos intereses "callejeros" que los alumnos quieren insertar en la dinámica escolar, que a la vez ante las condiciones sociales posmodernas llenas de individualización, hedonismo y diversidad también se resisten y actúan con mayor disciplina, tratando de enderezar los "malos comportamientos" de los alumnos.

"La lucha por la diferencia": se manifiesta en expresiones como las siguientes: 
“... muchas veces las orientadoras nos dicen que nos quitemos las arracadas, que nos cortemos el cabello, pero yo insisto en que ¿qué tiene que ver esto con la capacidad que uno tiene... traer el cabello pintado o más largo no tiene que ver con que uno sea más o menos inteligente, yo creo que eso nada tiene que ver... no estoy de acuerdo..."

“... en algunos casos el traer arracadas o cabello largo es una forma de expresión, se siente uno a gusto consigo mismo... es estar en la onda, traer arracadas significa estar a la moda, que ya estas como otros chavos, en mi caso, el cabello largo, me siento cómodo y me gusta traerlo, no quiero expresar nada..."

Pero además de esto, los alumnos aprecian incongruencias en el trato hacia los miembros de la comunidad educativa, pues se percibe que si algunas profesoras asisten maquilladas y los profesores traen los cabellos largos y ambos visten como quieren, entonces ¿porque a ellos no se les permite? En efecto parece ser que el alumno de este nivel se siente dominado, forzado a seguir ciertas reglas y pautas de comportamiento que no le son agradables y le llevan a sentirse incómodo y se diría enajenado a esta realidad que no ha construido y en la que no participa en su elaboración más que a través de sus actitudes de disidencia que desafían este ritualismo escolar moderno; expresiones como las anteriores y las siguientes corroboran lo afirmado:

“...así como nos exigen (las autoridades escolares), que den lo mismo, ¿porque no se cortan el pelo y se vienen con uniforme?..."

“...si nosotros nos vemos mal, es porque nos gusta... si no nos metemos con los maestros, o con los demás, entonces que nos respeten...".

Es aquí que la frase "ya no somos de Kinder o de primaria" se convierte en reclamo constante ante las circunstancias de esta escuela normalizadora que sigue con una fe ciega los preceptos de la modernidad. Giroux (1996) afirma que la escuela se ha caracterizado por ser un lugar en el que la disciplina, y el poder son prácticamente incuestionables, donde se sostiene una fe casi absoluta en la racionalidad científica técnica en la que el equilibrio y el orden son categorías fundamentales de la certidumbre; en ella "la contingencia es el enemigo y el orden la tarea" (154) Dentro de esta lógica, bajo el argumento de que la escuela es formadora, se imponen una serie de reglamentos que pretenden uniformar las conductas para el mantenimiento del orden preciado por los integrantes de mayor jerarquía en la escuela, incluyendo aquí al maestro. En esta pretensión la puntualidad y asistencia son 
puntos nodales en el orden escolar: nadie debe estar en el patio a la hora de las clases y debe existir un ambiente de silencio porque "el silencio es signo de que todos están trabajando"

Sin embargo existen mecanismos ante estas disposiciones que denotan un amplio conocimiento de las normas y su operatividad, de tal manera que incluso pueden llegar a infringirlas con un alto sentido de superioridad sobre el personal que se encarga de vigilarlas y hacerlas cumplir. A partir de lo anterior, se infiere que las oposiciones de los alumnos encuentran su significado en que es percibido y tratado por los actores escolares adultos como un menor de edad, irresponsable e incapaz de decidir lo que le conviene y lo que no; de alguna manera esto es sentido y vivido además de rechazado por ellos en la dinámica escolar, encontrando los resquicios que deja esta para expresar su inconformidad aún a través de la acomodación rebelde que se distingue por la simulación.

\section{REFELEXIONES FINALES}

La resistencia es una categoría que permite interpretar los comportamientos de los alumnos en el contexto escolar, pero ésta, desde la perspectiva de McLaren en tanto oposición a la disciplina escolar, es mejor comprendida cuando se toman en consideración las condiciones contextuales que la sociedad prismática mexicana de la ciudad de México: tradicional y moderna, pero sellada con rasgos posmodernos como el hedonismo, la personalización y el sin sentido, encuentran eco en una escuela normalizadora que lucha contra los deseos callejeros de estos que pareciera ser, están destinados a la exclusión a menos que desarrollen una acomodación menos rebelde a esas circunstancias.

Las actitudes de apatía escolar también encuentran mayor comprensión cuando se entiende que el contexto económico neoliberal de desigualdad extrema trae muy pocas perspectivas de seguridad a los alumnos, quienes ven en el auto empleo informal una fuente inagotable de libertad e ingresos que incluso superaría a los de profesionistas o cuando menos a los de sus maestros: representantes de un orden y casta que no son muy deseables por estos.

México es un país que se ha caracterizado por su búsqueda de capitales extranjeros históricamente reconocida y fuertemente criticada, hoy enfrentada a la volatilidad de las manufacturas y por tanto de las transnacionales extranjeras. Empresas sin patria diría Marx que difícilmente se comprometen con la población y gobierno de un solo país y que van a 
donde las condiciones para el lucro son mejores. Tan peleadas en países como el nuestro, India, China o Brasil entre otros que se disputan el dudoso privilegio de ofrecer las mejores condiciones para su implantación como son los y salarios y prestaciones más bajos posibles, en donde los gobiernos locales hacen lo posible para satisfacer estas demandas como ha sucedido en México con los gobiernos recientes que han posibilitado la eliminación y reducción en prestaciones obtenidas a través de los movimientos sociales del pasado.

En un país que ha implementado una de las políticas neoliberales mas ortodoxas del mundo desde hace más de 20 años y que ha dejado a la clase subordinada en condiciones de pobreza extrema en grandes proporciones de la misma, pero a la vez con varios de los hombres más ricos del planeta y, en una ciudad de México donde el subempleo es deseo porque finalmente es más seguro que el empleo y por tanto donde las cosas son al revés de lo que eran. Una ciudad donde el narcotráfico y sus agentes son en gran medida bien vistos, donde la delincuencia es ya experiencia compartida, es de esperar que los jóvenes que nacieron con estas condiciones, que no pertenecen al círculo de los empleados con buenos salarios, que son hijos de chóferes, comerciantes, etc., que no nacieron con la seguridad de las perspectivas, ni las perspectivas de seguridad, ni con la imagen de una escuela que resolvería sus angustias futuras si se esforzaban en ella, no esperen, en este sentido, que la escuela secundaria resuelva sus expectativas económico laborales, antes bien, lo que esperan es terminarla si es posible, para dedicarse a trabajar en lo suyo.

Así, la clase se ha convertido en un espacio de lucha contra el currículo y el maestro que lo encarna y lo atrapa, de pérdida del tiempo, según sus propias expresiones. La escuela aparece como una institución sufrible y a la vez inevitable para el logro de las credenciales necesarias para el mercado de trabajo. Estudiar y comprender este fenómeno, fuente de inequidad social, podría potenciar el desarrollo humano de los estudiantes, docentes y de las autoridades mismas en la búsqueda de relaciones sociales más justas y democráticas, donde la equidad se convierta en un fin a seguir a partir de realizar una reflexión crítica a la institución escolar y su pretensiones modernas de estandarización y control. 


\section{REFERENCIAS}

Bogdan, Robert y Taylor, Steven. (1996). Introducción a los métodos cualitativos de investigación. Buenos Aires: Paidós.

Bourdieu, Pierre. (1982). La Reproducción. México: Siglo XXI.

Buendía, Leonor y otros. (1998). Métodos de investigación en psicopedagogía. México: Mc Graw- Hill.

Colom, Antoni y Mélich, Joan Carles. (1997). Después de la modernidad. México: Paidós.

Foucault, Michel. (1988) Vigilar y castigar. Nacimiento de la prisión. México: Siglo XXI.

Giddens, Anthony. (1997). Modernidad e identidad del yo. El yo y la sociedad en la época contemporánea. Barcelona: Península.

Giroux, Henry y Mclaren, Peter. (1996). Sociedad, Cultura y Educación. Madrid: Instituto Paulo Freire, Miño y Dávila Editores.

Giroux, Henry. (1992). Teoría y resistencia en educación. México: Siglo XXI.

Giroux, Henry. (1996). Educación posmoderna y generación juvenil. Nueva Sociedad. (146), 148-167. Caracas: Edit. Texto.

Habermas, Jurgen. (1986). La modernidad, un proyecto incompleto. En La posmodernidad. (Selección y prólogo de Hal Foster). Barcelona: Kairós.

Hargreaves, Andy y otros. (2000). Una educación para el cambio. España: SEP-Octaedro.

Hargreaves, Andy. (2000) Profesorado, cultura y posmodernidad. Madrid: Morata.

Instituto Nacional de Evaluación Educativa. (2005). La calidad de la educación básica en México. Informe anual 2005. www.inee.edu.mx

Lipovetsky, Gilles. (2005). La era del vacío. Barcelona: Anagrama.

Lozano Andrade José Inés. (2005a). Reprobación y deserción en las escuelas secundaria del Distrito Federal: estado del conocimiento. México: UNICEF-GDF. Mimeo.

Lozano Andrade, José Inés. (2005b). Los significados de los alumnos hacia la escuela secundaria. Revista Iberoamericana de Educación. Setiembre de 2005. http://www.rieoei.org/deloslectores/1051Lozano.PDF

Lozano Andrade, José Inés. (2006). Normalistas vs. Universitarios o técnicos vs. Rudos. La formación y práctica del docente de secundaria desde sus representaciones sociales. México: Plaza y Valdés editores.

Mclaren, Peter. (1993). Pedagogía crítica, resistencia cultural y la producción del deseo. Buenos Aires: Rei-Aique. 
Mclaren, Peter. (1994). La escuela como un performance ritual. México: Paidós.

Mclaren, Peter. (1995). La vida en las escuelas. México: Siglo XXI.

Moscovici, Sergei. (1961). El psicoanálisis, su imagen y su público. Buenos Aires: Huemul.

Quiroz, Rafael. (2001, marzo). La educación secundaria en México al inicio del siglo XXI. Educación 2001. pp. 21-31.

Reimers Arias, Fernando. (1999, ene-mar). El estudio de las oportunidades educativas de los pobres en América Latina. Revista Latinoamericana De Estudios Educativos, 29 (1), 17-68. México.

Reimers, Fernando. (2000, ene-jun). ¿Pueden aprender los hijos de los pobres en las escuelas de América Latina? Revista Mexicana De Investigación Educativa, (México), 5 (9), 11-69.

Reforma Integral a la Escuela Secundaria. (2002). Documento base para la Reforma Integral de la Educación Secundaria. Subsecretaria de Educación Básica y Normal (Noviembre del 2002). México: SEP.

Sandoval Flores, Etelvina. (2000). La trama de la escuela secundaria: institución relaciones y saberes. México: Plaza y Valdés-UPN.

Secretaría de Educación Pública, México. (2005). Administración Federal de Servicios Educativos en el DF. Panorama de la educación secundaria en el DF. Bases para la acción.

Tedesco, Juan Carlos. (1996, noviembre-diciembre). La educación y los nuevos desafíos de la formación del ciudadano. Nueva sociedad. (146), 74-89. Caracas.

Torres Santomé, Jurjo. (1991). El Currículum Oculto. Madrid: Morata.

Vidal, Rafael; Díaz, María Antonieta. (2004). Resultados de las pruebas Pisa 2000 y 2003 en México. México: Instituto Nacional para la Evaluación de la Educación. 